\title{
Knowledge, attitude, and practice on and willingness to pay for human papillomavirus vaccine: a cross-sectional study in Hanoi,Vietnam
}

This article was published in the following Dove Press journal:

Patient Preference and Adherence

\author{
Bach Xuan Tran ${ }^{1,2}$ \\ Phung Tat Quoc Than ${ }^{3}$ \\ Tien Thuy Ngoc Doan' \\ Huong Lan Thi Nguyen ${ }^{4}$ \\ Hue Thi Mai' \\ Trang Huyen Thi Nguyen ${ }^{4}$ \\ Huong Thi Le' \\ Carl A Latkin ${ }^{2}$ \\ Melvyn WB Zhang ${ }^{5}$ \\ Roger CM Ho6
}

'Institute for Preventive Medicine and Public Health, Hanoi Medical University, Hanoi, Vietnam;

${ }^{2}$ Bloomberg School of Public Health, Johns Hopkins University, Baltimore, MD, USA; ${ }^{3}$ Department of Health Sciences, College of Health and Human Development, California State University, Northridge CA, USA; ${ }^{4}$ Institute for Global Health Innovations, Duy Tan University, Da Nang, Vietnam; ${ }^{5}$ Biomedical Global Institute of Healthcare Research \& Technology (BIGHEART), National University of Singapore, Singapore; ${ }^{6}$ Department of Psychological Medicine, Yong Loo Lin School of Medicine, National University of Singapore, Singapore
Correspondence: Bach Xuan Tran Bloomberg School of Public Health, Johns Hopkins University, 615 N Wolfe St, Baltimore, MD 2/205, USA

Tel +84 888288399

Email bach.ipmph@gmail.com
Background: Despite its effectiveness in preventing human papillomavirus (HPV) infection, the rate of uptake of the HPV vaccine is low in Vietnam. This study aimed to investigate barriers related to knowledge-attitude-practice (KAP) about the HPV vaccine and willingness to pay (WTP) for the vaccine among those using services in an urban vaccination clinic in Hanoi, Vietnam.

Materials and methods: A cross-sectional study was conducted in a vaccination clinic of the Institute for Preventive Medicine and Public Health in Hanoi, Vietnam, from March to April 2016. KAP on the HPV vaccine was collected using a structured questionnaire. Double-bounded dichotomous-choice questions with open-ended questions were used to examine the WTP of respondents. Interval regression and stepwise logistic models were used to identify factors associated with WTP and the average amount that people would be willing to pay for the vaccine. Results: Of 492 vaccination service users, $67.9 \%, 94.6 \%$, and $12.3 \%$ of respondents were aware of the best age for HPV vaccination, its benefits, and the target group for vaccination, respectively. While the majority believed that the HPV vaccine was safe (92.8\%) and effective $(90.8 \%)$, and desired to be vaccinated $(71.1 \%)$, only $31.8 \%$ of users were vaccinated. Most of the respondents were willing to pay for the HPV vaccine $(86.6 \%)$, and willing to pay an average amount of US\$49.3. Those aged 20-29 years and earning more than 22 million VND/ month (very rich) were more likely to pay for the HPV vaccine than people aged $<20$ years and earning $<7$ million VND/month. Users who had attained more than a high-school education and heard about the HPV vaccine from doctors, nurses, or other health professionals tended to be willing to pay for the vaccine at a lower price than individuals with below secondary-level education and who had not heard about the vaccine from these health professionals.

Conclusion: Sexual health education and financial assistance should be imparted alongside the HPV vaccination program.

Keywords: willingness to pay, knowledge, attitude, practice, HPV vaccine, Vietnam

\section{Introduction}

Human papillomavirus (HPV) is associated with various cancer types in both men and women. Among women, in 2012, HPV was associated with $74 \%$ of cancer cases, $70 \%$ of which were cervical cancer. ${ }^{1}$ In men, HPV DNA is detected in around $50 \%$ of all penile cancers. ${ }^{2}$ HPV 16, HPV 18, and HPV 6/11 are considered the most common causes of HPV-related penile tumors. ${ }^{3}$

HPV vaccination is an effective method to diminish the risk of HPV transmission in both genders. ${ }^{5}$ In 2008, the US Food and Drug Administration licensed the first vaccine that could prevent $70 \%$ of cervical cancers and diseases associated with HPV 16 and 
HPV 18. A systematic review of cost-effectiveness analyses endorsed the need for HPV vaccine combined with screening tests to reduce costs, save time, and prolong the effects of the vaccine. ${ }^{4}$ However, in developing countries, the uptake of HPV immunization among the target population remains low. ${ }^{12-14}$ One study revealed that HPV vaccine uptake among Vietnamese young people (5.7\%) was significantly lower than that of their US counterparts (42\%). ${ }^{15}$ Reasons for this phenomenon include high cost, ${ }^{6,7}$ lack of knowledge about the HPV vaccine,${ }^{8}$ negative attitudes toward the HPV vaccine, ${ }^{9}$ and fear of side effects. ${ }^{10,11}$ Moreover, empirical evidence indicated that the integration of HPV vaccination into preventive strategies may face several barriers related to knowledge, attitude, practice, and willingness to pay (WTP) for this vaccine. ${ }^{16,17}$

The Ministry of Health in Vietnam has exempted fees for vaccine services to children aged under 6 years, but people need the provide co-payment for other vaccines such as rubella, Haemophilus influenzae, hepatitis B, and HPV vaccines. ${ }^{18}$ During 2006-2010, the Vietnam National Institute of Hygiene and Epidemiology collaborated with the Program for Appropriate Technology in Health to implement school-based and health center-based HPV vaccine demonstration projects to 11 -year-old females. ${ }^{19}$ The project ended successfully and gained a high level of public acceptability. ${ }^{20}$ Since 2016, the country has no longer qualified for support from the Global Alliance for Vaccines and Immunization. ${ }^{21}$ People have to pay the full price for each dose of HPV vaccine, which costs around US\$100, and this could be a financial burden.

Our study aimed to investigate knowledge-attitudepractice (KAP), WTP, and factors associated with WTP for the HPV vaccine among those using the services of an urban vaccination clinic in Hanoi, Vietnam. Our findings could be useful for the Ministry of Health in Vietnam, which is considering incorporating HPV vaccination into the national Expanded Program on Immunization.

\section{Materials and methods}

\section{Study setting and sampling method}

We conducted a cross-sectional study at the Institute of Preventive Medicine and Public Health vaccination clinic, Hanoi, Vietnam, from March to April 2016. We chose this clinic based on several factors. First, it is located in the center of Hanoi; thus, the characteristics of users were likely to reflect the dynamic socioeconomic characteristics of urban people. Second, this clinic has sufficient service users to meet the study sample size. Subjects were included in the study if they met the eligibility criteria: 1) were vaccine service users, 2) were at least 18 years old, 3) agreed to enroll in the study and signed a written informed consent, and 4) were cognitively healthy.

Under the scope of this study, a convenience sampling approach was applied to recruit both male and female participants. This method allowed us to reach all available subjects in the clinic where the sampling frame was not available. After eligible subjects provided written informed consent to confirm they were invited to a private room for face-to-face interviews to ensure confidentiality. A total of 429 subjects participated in this study.

\section{Measurements and instruments}

Face-to-face interviews were conducted using a structured questionnaire to collect self-reported data. We were aware that our study might be affected by recall bias and social desirability bias. The former bias could occur when service users incompletely remember events in the past, while the latter bias may occur when respondents want to please the medical staff, resulting in overestimating or underestimating the outcomes of interest. We applied several solutions to address these biases. First, we recruited interviewers who were not affiliated with the vaccination clinic and received sufficient training. Second, the interviewers explained clearly the purpose of the study to the subjects before interviewing and allowed sufficient time for subjects to recall accurate memories. Third, the questionnaire was designed in an understandable way. Finally, because some couples brought their children to the clinic together, we ensured that the mother and father were not interviewed twice by checking when we invited them to the study.

\section{Sociodemographic characteristics}

We collected data about age, gender, educational attainment, marital status, current occupation, and monthly household income.

\section{Knowledge, attitude, and practice about HPV vaccination}

Since a validated questionnaire is not available in Vietnam, we developed a series of questions based on previous studies in settings with a similar sociocultural context to Vietnam to examine KAP about HPV vaccination, and conducted a pilot study to test the validity and reliability of the questionnaire. Knowledge about HPV vaccination was measured by asking the respondents about the target group for HPV vaccination, benefits of HPV vaccination, and the best age 
for vaccination. In terms of attitude, we asked people about their belief in the safety and efficacy of the vaccine and their desire for vaccine uptake by asking the following questions: "Do you believe that HPV vaccine is safe?", "Do you believe that HPV vaccine is efficient?", and "Do you want to get the HPV vaccine?" In terms of practice, we asked whether subjects have received HPV vaccinations before and, if not, the reasons why they had not received the vaccine.

\section{Willingness to pay for HPV vaccination}

We used a contingent valuation method to examine the WTP for HPV vaccination services, with a starting price of 1.8 million VND ( US\$81, 2016 exchange rate) (Figure 1). First, subjects were asked "Are you willing to pay 1.8 million VND per dose for HPV vaccine?" The price doubled or dropped by a half depending on the respondent's answer (Yes or No). The question was repeated until the last price reached four times higher or eight times lower than the initial price. Finally, subjects were asked about the maximum price that they were willing to pay for a dose of HPV vaccine.

\section{Statistical analysis}

Data were analyzed using STATA software (version 12.0). For missing data, the highest proportion of missing data was $6.1 \%$, for the desire to be vaccinated. The chi-squared test was used to assess differences in sociodemographic variables (age, education, marital status, and occupation), sources of seeking HPV information, KAP about the HPV vaccine, sexually transmitted infections (STIs), and use of reproductive health services between the genders. Logistic and interval regressions were used to identify factors associated with WTP and the amount that people were willing to pay.
A forward stepwise strategy with a threshold of $p<0.2$ was applied to shorten the regression model. A $p$-value $<0.05$ was considered statistically significant.

\section{Ethics approval and informed consent}

The study was approved by Ethical Committee of Hanoi Medical University. Subjects were told about the purpose of this study and asked to give their written informed consent if they agreed to participate in the study. Subjects could withdraw from the study at any time without any interruption of their services at the clinic. They were assured that their information would remain confidential.

\section{Results}

The majority of the sample had received at least a highschool level of education (63.2\%). Half of the respondents were single, divorced, or widowed $(50.6 \%)$. The mean \pm SD age was $26.8 \pm 6.2$ years and the average monthly household income was 15.9 \pm 32.2 million VND (Table 1).

Table 2 presents the different ways of seeking HPVrelated information. Social networks and the internet (56.8\%), and doctors, nurses, and other health professionals (41.9\%) were common channels used to obtain information on the HPV vaccine. Of note, the internet, news, and television were the most popular channels used to seek HPV vaccine information, accounting for $66.8 \%$. The rate of seeking HPV vaccine information in females was significantly higher than that in males $(p<0.01)$.

Table 3 summarizes KAP about HPV vaccination. The percentages of subjects correctly answering questions regarding the best age for HPV vaccination, the benefits of HPV vaccination, and the target subject for HPV vaccination were $67.9 \%, 94.6 \%$, and $12.3 \%$, respectively.

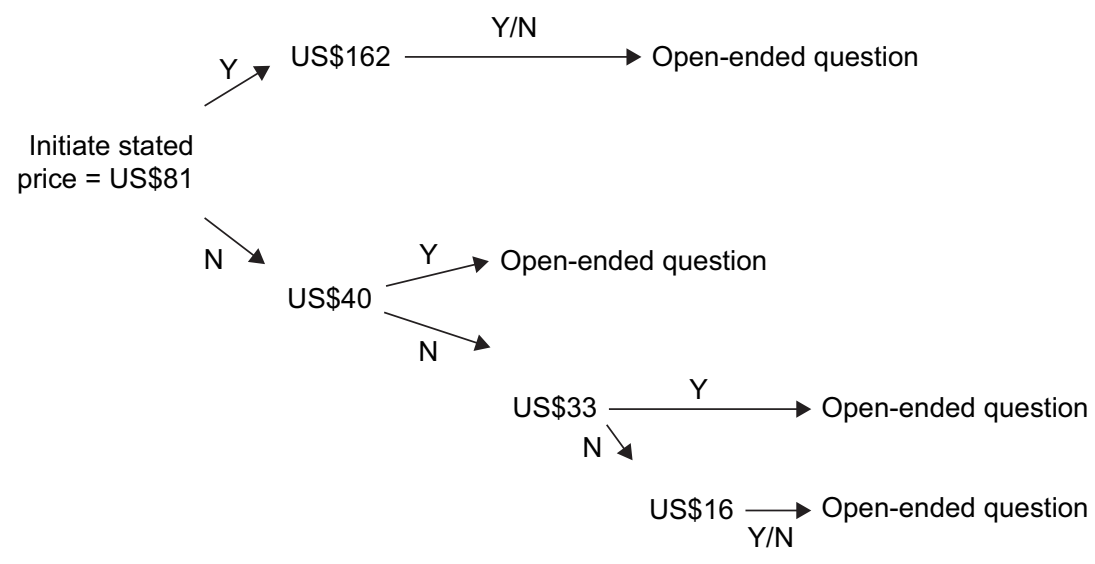

Figure I Contingent valuation of willingness to pay. Abbreviations: $\mathrm{Y}$, yes; $\mathrm{N}$, no. 
Table I Characteristics of respondents

\begin{tabular}{|c|c|c|c|c|c|c|c|}
\hline \multirow[t]{2}{*}{ Characteristics } & \multicolumn{2}{|c|}{ Female } & \multicolumn{2}{|l|}{ Male } & \multicolumn{2}{|l|}{ Total } & \multirow[t]{2}{*}{$p$-value } \\
\hline & $\mathbf{n}$ & $\%$ & $\mathbf{n}$ & $\%$ & $\mathbf{n}$ & $\%$ & \\
\hline Age (years) & & & & & & & $<0.05$ \\
\hline$\leq 25$ & 118 & 37.6 & 62 & 54.8 & 180 & 42.2 & \\
\hline $25-40$ & 180 & 57.3 & 44 & 38.9 & 224 & 52.5 & \\
\hline$>40$ & 16 & 5.1 & 7 & 6.2 & 23 & 5.4 & \\
\hline Ethnicity & & & & & & & 0.09 \\
\hline Kinh & 308 & 98.4 & 108 & 95.6 & 416 & 97.7 & \\
\hline Other & 5 & 1.6 & 5 & 4.4 & 10 & 2.4 & \\
\hline Educational level & & & & & & & $<0.01$ \\
\hline Secondary school or less & 13 & 4.1 & 2 & 1.8 & 15 & 3.5 & \\
\hline High school & 85 & 27.1 & 57 & 50.4 & 142 & 33.3 & \\
\hline Greater than high school & 216 & 68.8 & 54 & 47.8 & 270 & 63.2 & \\
\hline Religion & & & & & & & 0.01 \\
\hline None & 308 & 98.7 & 106 & 93.8 & 414 & 97.4 & \\
\hline Other & 4 & 1.3 & 7 & 6.2 & 11 & 2.6 & \\
\hline Marital status & & & & & & & $<0.01$ \\
\hline Single/divorced/widowed & 138 & 44.0 & 78 & 69.0 & 216 & 50.6 & \\
\hline Living with spouse/partner & 176 & 56.1 & 35 & 31.0 & 211 & 49.4 & \\
\hline Occupation & & & & & & & $<0.01$ \\
\hline Freelancer & 34 & 11.0 & 12 & 10.6 & 46 & 10.9 & \\
\hline White-collar worker & 149 & 48.1 & 34 & 30.1 & 183 & 43.3 & \\
\hline Student & 100 & 32.3 & 60 & 53.1 & 160 & 37.8 & \\
\hline \multirow[t]{2}{*}{ Other } & 27 & 8.7 & 7 & 6.2 & 34 & 8.0 & \\
\hline & Mean & SD & Mean & SD & Mean & SD & $p$-value \\
\hline Age (years) & 27.0 & 5.7 & 26.3 & 7.6 & 26.8 & 6.2 & 0.31 \\
\hline $\begin{array}{l}\text { Monthly household income } \\
\left.\text { (million VND }{ }^{a}\right)\end{array}$ & 14.3 & 11.3 & 20.0 & 58.0 & 15.9 & 32.2 & 0.46 \\
\hline
\end{tabular}

Note: ${ }^{\text {a } ~ U S ~} \$=22,222$ Vietnamese dong (VND).

Regarding attitudes, the majority believed that the HPV vaccine was safe $(92.8 \%)$ and effective $(90.8 \%)$, and desired to get vaccinated $(71.1 \%)$. However, the vaccination rate was only $31.8 \%$, and the vaccination rate in males was nearly four times lower than in females $(p<0.01)$. The most common reasons for not having the HPV vaccine were being male (33.3\%), high cost (38.2\%), and the vaccine being seen as unnecessary $(34.5 \%)$.

Table 2 Finding information on the HPV vaccine

\begin{tabular}{|c|c|c|c|c|c|c|c|}
\hline \multirow[t]{2}{*}{ Characteristics } & \multicolumn{2}{|c|}{ Female } & \multicolumn{2}{|c|}{ Male } & \multicolumn{2}{|c|}{ Total } & \multirow[t]{2}{*}{ p-value } \\
\hline & $\bar{n}$ & $\%$ & $\bar{n}$ & $\%$ & $\bar{n}$ & $\%$ & \\
\hline Heard about HPV vaccine & 276 & 91.4 & 87 & 77.7 & 363 & 87.7 & $<0.01$ \\
\hline Seeking HPV vaccination information & 233 & 84.4 & 46 & 52.9 & 279 & 76.9 & $<0.01$ \\
\hline \multicolumn{8}{|l|}{ Source of hearing about HPV vaccine } \\
\hline Friends & 52 & 22.5 & 8 & 16.7 & 60 & 21.5 & 0.37 \\
\hline Relatives & 49 & 21.2 & 4 & 8.7 & 53 & 19.1 & 0.05 \\
\hline Doctors/nurses/health professionals & 99 & 42.9 & 18 & 37.5 & 117 & 41.9 & 0.49 \\
\hline Books/newspapers & 65 & 28.1 & 14 & 29.8 & 79 & 28.4 & 0.82 \\
\hline Social network/internet & 134 & 58.0 & 24 & 51.1 & 158 & 56.8 & 0.38 \\
\hline \multicolumn{8}{|l|}{ Source for finding HPV vaccine information } \\
\hline Community health worker & 29 & 11.5 & 4 & 5.8 & 33 & 10.3 & 0.17 \\
\hline Staff at vaccination clinic & 74 & 29.0 & 8 & 11.6 & 82 & 25.3 & $<0.01$ \\
\hline Internet/news/television & 167 & 65.2 & 50 & 72.5 & 217 & 66.8 & 0.26 \\
\hline National guideline & 13 & 5.1 & 3 & 4.4 & 16 & 5.0 & 0.79 \\
\hline Relatives/friends/colleagues & 95 & 37.0 & 23 & 33.3 & 118 & 36.2 & 0.58 \\
\hline Other & II & 4.2 & 9 & 11.5 & 20 & 5.9 & 0.02 \\
\hline
\end{tabular}

Abbreviation: HPV, human papillomavirus. 
Table 3 Knowledge-attitude-practice about the HPV vaccine

\begin{tabular}{|c|c|c|c|c|c|c|c|}
\hline \multirow[t]{2}{*}{ Characteristics } & \multicolumn{2}{|c|}{ Female } & \multicolumn{2}{|c|}{ Male } & \multicolumn{2}{|c|}{ Total } & \multirow[t]{2}{*}{$\overline{p \text {-value }}$} \\
\hline & $\mathbf{n}$ & $\%$ & $n$ & $\%$ & $\mathbf{n}$ & $\%$ & \\
\hline \multicolumn{8}{|l|}{ Knowledge about HPV vaccine } \\
\hline \multicolumn{8}{|l|}{ Targeted subject for HPV vaccination } \\
\hline Male & 32 & 11.9 & 15 & 19.5 & 47 & 13.6 & 0.09 \\
\hline Female & 264 & 98.5 & 77 & 100.0 & 341 & 98.8 & 0.28 \\
\hline Both male and female & 28 & 10.3 & 15 & 19.2 & 43 & 12.3 & $<0.05$ \\
\hline \multicolumn{8}{|l|}{ Benefits of HPV vaccine } \\
\hline Prevent cervical cancer & 263 & 97.2 & 67 & 86 & 330 & 94.6 & $<0.01$ \\
\hline Treat cervical cancer & 2 & 0.8 & 4 & 5.1 & 6 & 1.7 & \\
\hline Unknown & 7 & 2.6 & 9 & 11.5 & 16 & 4.6 & \\
\hline \multicolumn{8}{|l|}{ Places providing HPV vaccine service } \\
\hline Hospital & 145 & 56.9 & 48 & 68.6 & 193 & 59.4 & 0.08 \\
\hline Immunization facility & 221 & 87.0 & 56 & 80.0 & 277 & 85.5 & 0.14 \\
\hline \multicolumn{8}{|l|}{ Age for highest effectiveness of vaccine } \\
\hline 9-25 years, never had sex & 197 & 73.0 & 38 & 50.0 & 235 & 67.9 & $<0.01$ \\
\hline $9-25$ years & 24 & 8.9 & 4 & 5.3 & 28 & 8.1 & \\
\hline Before having sex & 6 & 2.2 & 2 & 2.6 & 8 & 2.3 & \\
\hline Other & 30 & 11.1 & 20 & 26.3 & 50 & 14.5 & \\
\hline Unknown & 13 & 4.8 & 12 & 15.8 & 25 & 7.2 & \\
\hline \multicolumn{8}{|l|}{ Attitude about HPV vaccine } \\
\hline Believes that HPV vaccine is safe & 251 & 92.6 & 70 & 93.3 & 321 & 92.8 & 0.83 \\
\hline \multicolumn{8}{|l|}{ Believes that HPV vaccine is effective } \\
\hline Yes & 244 & 90.0 & 70 & 93.3 & 314 & 90.8 & 0.63 \\
\hline No & 8 & 3.0 & I & 1.3 & 9 & 2.6 & \\
\hline Unknown & 19 & 7.0 & 4 & 5.3 & 23 & 6.7 & \\
\hline \multicolumn{8}{|l|}{ Desire to have HPV vaccine injection } \\
\hline Yes, certainly & 212 & 78.5 & 54 & 72.0 & 266 & 77.1 & 0.36 \\
\hline Possibly & 53 & 19.6 & 18 & 24.0 & 71 & 20.6 & \\
\hline No & 5 & 1.9 & 3 & 4.0 & 8 & 2.3 & \\
\hline \multicolumn{8}{|c|}{ Most influential person to inject HPV vaccine } \\
\hline Doctor/nurse/health professional & 96 & 32.2 & 38 & 34.9 & 134 & 32.9 & 0.62 \\
\hline Teacher & 15 & 5.0 & 4 & 3.7 & 19 & 4.7 & 0.58 \\
\hline Friend & 23 & 7.7 & 17 & 15.6 & 40 & 9.8 & 0.02 \\
\hline Family & 48 & 16.1 & 18 & 16.5 & 66 & 16.2 & 0.92 \\
\hline Oneself & 127 & 42.6 & 37 & 34.6 & 164 & 40.5 & 0.15 \\
\hline Other & 4 & 1.3 & 3 & 2.7 & 7 & 1.7 & 0.33 \\
\hline \multicolumn{8}{|l|}{ Practice of HPV vaccine } \\
\hline Has ever had HPV vaccine injection & 102 & 37.6 & 8 & 10.7 & 110 & 31.8 & $<0.01$ \\
\hline \multicolumn{8}{|l|}{ Reason not to inject } \\
\hline High cost & 51 & 56.0 & 7 & 11.5 & 58 & 38.2 & $<0.01$ \\
\hline Unnecessary & 39 & 44.3 & 12 & 20.0 & 51 & 34.5 & $<0.01$ \\
\hline Male & 3 & 3.7 & 44 & 73.3 & 47 & 33.3 & $<0.01$ \\
\hline Unsuitable age & 49 & 30.6 & 2 & 2.9 & 51 & 22.4 & $<0.01$ \\
\hline Lack of knowledge & 14 & 8.8 & 4 & 5.9 & 18 & 7.9 & 0.46 \\
\hline Not sufficient condition & 14 & 8.8 & 1 & 1.5 & 15 & 6.6 & $<0.05$ \\
\hline Lack of trust & 2 & 1.3 & 0 & 0.0 & 2 & 0.9 & 0.35 \\
\hline Using other vaccine & I & 0.6 & 0 & 0.0 & I & 0.4 & 0.51 \\
\hline Afraid of pain & I & 0.6 & 0 & 0.0 & 1 & 0.4 & 0.51 \\
\hline
\end{tabular}

Abbreviation: HPV, human papillomavirus.

The subjects' history of STIs and use of reproductive health service are shown in Table 4. Most subjects had never been infected with STIs (90.1\%) or genital herpes (94.4\%). Nearly $30 \%$ of subjects had ever had a reproductive health examination, and $46 \%$ of these respondents were examined every 6 months.
The WTP for the HPV vaccine is presented in Table 5. Most respondents were willing to pay for the HPV vaccine (86.6\%), with an average amount of 1.119 million VND.

Table 6 shows that those aged 20-29 years were more likely to be willing to pay for HPV vaccine than those aged $<20$ years $(\mathrm{OR}=6.99,95 \%$ CI 1.62 to 30.21$)$. 
Table 4 History of STIs and reproductive health service use

\begin{tabular}{|c|c|c|c|c|c|c|c|}
\hline \multirow[t]{2}{*}{ Characteristics } & \multicolumn{2}{|c|}{ Female } & \multicolumn{2}{|c|}{ Male } & \multicolumn{2}{|c|}{ Total } & \multirow[t]{2}{*}{$p$-value } \\
\hline & $n$ & $\%$ & $\mathbf{n}$ & $\%$ & n & $\%$ & \\
\hline \multicolumn{7}{|l|}{ Ever had STI } & 0.08 \\
\hline Yes & 27 & 8.9 & 3 & 2.7 & 30 & 7.3 & \\
\hline No & 268 & 88.7 & 104 & 93.7 & 372 & 90.1 & \\
\hline Unknown & 7 & 2.3 & 4 & 3.6 & II & 2.7 & \\
\hline \multicolumn{7}{|l|}{ Ever had genital herpes } & 0.39 \\
\hline Yes & 5 & $\mathrm{I} .7$ & 3 & 2.7 & 8 & 1.9 & \\
\hline No & 283 & 94.0 & 106 & 95.5 & 389 & 94.4 & \\
\hline Unknown & 13 & 4.3 & 2 & 1.8 & 15 & 3.6 & \\
\hline \multicolumn{7}{|l|}{ Family member ever had STI } & 0.24 \\
\hline Yes & 7 & 2.3 & 0 & 0.0 & 7 & 1.7 & \\
\hline No & 272 & 90.1 & 104 & 93.7 & 376 & 91.0 & \\
\hline Unknown & 23 & 7.6 & 7 & 6.3 & 30 & 7.3 & \\
\hline \multicolumn{7}{|c|}{ Knows people who have had cervical cancer } & 0.23 \\
\hline Yes & 12 & 4.0 & I & 0.9 & 13 & 3.1 & \\
\hline No & 277 & 91.1 & 107 & 95.5 & 384 & 92.3 & \\
\hline Unknown & 15 & 4.9 & 4 & 3.6 & 19 & 4.6 & \\
\hline Ever examined reproductive health & 105 & 34.8 & 6 & 5.4 & III & 26.9 & $<0.01$ \\
\hline \multicolumn{7}{|c|}{ Frequency of reproductive health examination } & 0.09 \\
\hline Every 3 months & 14 & 13.3 & 3 & 50.0 & 17 & 15.3 & \\
\hline Every 6 months & 50 & 47.6 & I & 16.7 & 51 & 46.0 & \\
\hline Every I year & 33 & 31.4 & 2 & 33.3 & 35 & 31.5 & \\
\hline Over I year & 8 & 7.6 & 0 & 0.0 & 8 & 7.2 & \\
\hline
\end{tabular}

Abbreviation: STI, sexually transmitted infection.

People who earned more than 22 million VND/month (very rich) were willing to pay for HPV vaccine at a higher price than those who earned $<7$ million/month (very poor) (coefficient $=474.91,95 \%$ CI 82.19 to 867.63 ). Service users who had attained education above high school were will- ing to pay for the vaccine at a lower price than those had less than secondary education (coefficient $=-572.98,95 \%$ CI -936.33 to -209.64). Those who had children above 6 years old were willing to pay a higher price for the HPV vaccine $($ coefficient $=1,294.77,95 \%$ CI 161.91 to $2,427.63$ ).

Table 5 WTP for the HPV vaccine

\begin{tabular}{|c|c|c|c|c|c|}
\hline \multirow[t]{2}{*}{ Characteristics } & \multicolumn{3}{|c|}{ WTP } & \multicolumn{2}{|c|}{ Amount willing to pay (VND) } \\
\hline & n & $\%$ & $\overline{p \text {-value }}$ & Mean & $95 \% \mathrm{Cl}$ \\
\hline Total & 349 & 86.6 & & $1,119.9$ & $1,010.3$ to $1,229.4$ \\
\hline Gender & & & 0.18 & & \\
\hline Female & 256 & 88.0 & & $\mathrm{I}, 084.0$ & 962.1 to $1,206.0$ \\
\hline Male & 92 & 82.9 & & $1,231.7$ & 990.9 to $1,472.6$ \\
\hline Age (years) & & & 0.97 & & \\
\hline$<20$ & 8 & 88.9 & & $1,523.1$ & 619.1 to $2,427.1$ \\
\hline $20-29$ & 248 & 86.7 & & $1,119.9$ & 993.4 to $1,246.3$ \\
\hline$\geq 30$ & 93 & 86.1 & & $1,084.6$ & 864.0 to $1,305.3$ \\
\hline Educational level & & & 0.86 & & \\
\hline Secondary school or less & 11 & 91.7 & & 782.7 & 243.7 to $1,321.6$ \\
\hline High school & 119 & 86.9 & & $1,279.0$ & $\mathrm{I}, 085.2$ to $\mathrm{I}, 472.8$ \\
\hline More than high school & 218 & 86.2 & & $\mathrm{I}, 056.7$ & 920.3 to $I, 193.1$ \\
\hline Marital status & & & 0.65 & & \\
\hline Single/divorced/widowed & 179 & 87.3 & & $1,141.9$ & 993.4 to $I, 290.5$ \\
\hline Living with spouse/partner & 169 & 85.8 & & $1,101.8$ & 939.4 to $1,264.3$ \\
\hline Employment & & & 0.13 & & \\
\hline Freelancer & 33 & 75.0 & & 864.3 & 568.6 to $1,160.0$ \\
\hline White-collar worker & 152 & 88.4 & & $\mathrm{I}, 107.8$ & 936.9 to $1,278.7$ \\
\hline Student & 134 & 87.6 & & $1,202.9$ & $\mathrm{I}, 022.4$ to $1,383.4$ \\
\hline Other & 27 & 87.1 & & $1,230.6$ & 838.1 to $1,623.0$ \\
\hline
\end{tabular}

Abbreviations: WTP, willingness to pay; HPV, human papillomavirus. 
Table 6 Factors associated with WTP and amount willing to pay for the HPV vaccine

\begin{tabular}{|c|c|c|c|c|}
\hline \multirow[t]{2}{*}{ Characteristics } & \multicolumn{2}{|c|}{ WTP for HPV vaccine } & \multicolumn{2}{|c|}{ Amount willing to pay (VND) } \\
\hline & OR & $95 \% \mathrm{Cl}$ & Coefficient & $95 \% \mathrm{Cl}$ \\
\hline \multicolumn{5}{|l|}{ Vaccine service user (vs children) } \\
\hline Adult male & $0.12^{* * *}$ & 0.03 to 0.52 & -271.32 & -664.03 to 121.40 \\
\hline \multicolumn{5}{|l|}{ Age (vs <20 years) } \\
\hline 20-29 years & $6.99 * * *$ & 1.62 to 30.21 & & \\
\hline$\geq 30$ years & & & $-323.6 I *$ & -683.20 to 35.98 \\
\hline \multicolumn{5}{|l|}{ divorced/widowed) } \\
\hline \multicolumn{5}{|l|}{ Education (vs secondary school or less) } \\
\hline High school & 3.30 & 0.72 to 15.06 & & \\
\hline More than high school & & & $-572.98 * * *$ & -936.33 to -209.64 \\
\hline \multicolumn{5}{|l|}{ Employment (vs freelancer) } \\
\hline White-collar worker & $6.00 * *$ & 1.35 to 26.59 & & \\
\hline \multicolumn{5}{|l|}{ Household income (million VND/month) } \\
\hline \multicolumn{5}{|l|}{ (vs $<7$ million $\mathrm{VND/month,} \mathrm{very} \mathrm{poor)}$} \\
\hline $7-10$ (poor) & $0.28 * *$ & 0.09 to 0.95 & & \\
\hline 10-20 (rich) & & & 303.64 & $-102.5 \mid$ to 709.79 \\
\hline 20-600 (very rich) & $11.61^{*}$ & 0.66 to 203.74 & $474.91 * *$ & 82.19 to 867.63 \\
\hline \multicolumn{5}{|l|}{ Has children (vs no children) } \\
\hline Has children $>6$ years old & & & $\mathrm{I}, 294.77 * *$ & $161.9 \mid$ to $2,427.63$ \\
\hline \multicolumn{5}{|l|}{ Source of hearing about HPV (vs no) } \\
\hline Doctors/nurses/health professionals & $0.18^{* * *}$ & 0.05 to 0.59 & $-443.34 * * *$ & -719.17 to -167.51 \\
\hline Social network/internet & & & 204.28 & -79.47 to 488.03 \\
\hline \multicolumn{5}{|l|}{ Source for finding HPV information (vs no) } \\
\hline Community health worker & & & $-550.15^{* * *}$ & -967.00 to $-|33.3|$ \\
\hline Website/newspaper/television & & & $-324.5 I^{* *}$ & -616.88 to -32.14 \\
\hline Believes that HPV vaccine is safe (yes vs no) & & & $440.58^{*}$ & -20.91 to 902.07 \\
\hline Believes that HPV vaccine is effective (yes vs no) & $0.08 * *$ & 0.01 to 0.62 & & \\
\hline Has ever examined reproductive health (yes vs no) & $0.23 * *$ & 0.06 to 0.91 & & \\
\hline Has family member who ever had STI (yes vs no) & $13.26 *$ & 0.73 to 241.17 & & \\
\hline
\end{tabular}

Note: $* * * p<0.01$, ** $p<0.05$, *p<0.1.

Abbreviations: HPV, human papillomavirus; WTP, willingness to pay; VND, Vietnamese dong; STI, sexually transmitted infection.

People who were informed about HPV by doctors, nurses, or other health professionals were willing to pay a lower price for the HPV vaccine (coefficient $=-443.34,95 \% \mathrm{CI}-719.17$ to -167.51$)$.

\section{Discussion}

This study provides a step toward a better understanding of barriers to HPV vaccination uptake in Hanoi, Vietnam. Our findings highlighted a low rate of service users having sufficient KAP towards HPV vaccination, but a high proportion of respondents were willing to pay for HPV vaccine, at an average cost of 1.119 million VND (US\$49.3) per dose. Moreover, some factors associated with the WTP for HPV vaccine were found, suggesting potential implications for further scaling-up of HPV vaccination in Vietnam.

In this study, we found that one-third of service users were vaccinated against HPV infection. This vaccine uptake rate $(31.8 \%)$ was higher than a previous study in Vietnam $(2.3 \%)^{24}$ but lower than a study in China (47.2\%), and in European countries such as Germany $(53 \%)^{25}$ and the Netherlands (49.9\%). ${ }^{26}$ Of note, we observed that very few people answered correctly the question about the target group for HPV vaccination. This may be explained by the fact that HPV vaccination programs have largely focused on women and young adolescent girls as there is a close link to cervical cancer. ${ }^{22}$ However, this may lead to erroneous perceptions of the target group for HPV vaccination in that this vaccine is for both males and females. Moreover, men may perceive that the HPV vaccine is not necessary. ${ }^{23}$ This raises the need for knowledge enhancement efforts which emphasize the benefits of HPV vaccination in both men and women.

The estimated amount that people were willing to pay for the HPV vaccine in this sample was approximately twothirds of the actual price in the vaccination clinic (1.8 million VND per dose). This amount was lower than that in the USA, ${ }^{27}$ where mothers would pay an average of US\$663 for the three-dose course. In other studies in Thailand and Mexico, people were willing to pay US\$200 for three doses 
and US\$45-240 for three doses, ${ }^{28}$ respectively. The reason for this may be because this amount could still be a financial burden as the three-dose HPV vaccine course represented about $21 \%$ of general monthly household income and nearly $7 \%$ of Vietnamese annual income. ${ }^{29}$ A previous study conducted in Binh Dinh, Vietnam, also indicated the high cost as a major barrier to HPV vaccination. ${ }^{24}$ Our results highlight the need for financial support and the inclusion of the HPV vaccine in the National Immunization Program.

Our findings suggest that individuals between the ages of 20 and 29 years were most likely to pay for the vaccine. Sexual health topics are often avoided in discussions at school or in the family. ${ }^{30}$ Some people even believe that sexuality and relationships are not appropriate for adolescents and young adults because education must be prioritized. ${ }^{31}$ However, this may lead to a lack of essential knowledge about sexual health. In the context of Vietnam, those between 20 and 29 years old are more likely than others to be in a romantic relationship, become sexually active, and care about sexual health. Thus, the expansion of school-based sexual health education could be a vital aspect of any public health initiative to increase the knowledge regarding prevention of STIs. Although receiving HPV vaccination before becoming sexually active can reduce the risk of cervical cancer, the rate of vaccination uptake remains low owing to high prices, especially in developing countries. ${ }^{32}$ Very rich subjects were more willing to pay the higher price than their very poor counterparts. While this result is in line with a previous study in Vinh Long, Vietnam, ${ }^{18}$ a study in Binh Dinh, Vietnam, found no association between household economics and HPV vaccination. ${ }^{24}$ Nevertheless, our study affirms the existence of financial barriers to HPV vaccination.

This study suggests that those had higher than a highschool level of education tended to pay for the vaccine at a lower price than those who had lower than the secondaryschool level. This finding is in line with the previous literature. ${ }^{33,34}$ It is widely acknowledged that well-educated people tend to chart their own course on the issue of vaccines. ${ }^{35,36}$ In this respect, these people may enrich their knowledge themselves by cross-referencing reputable information on the internet, where they gather a lot of misinformation about vaccination. While a large body of literature shows that physicians play an important role in increasing HPV vaccine uptake, ${ }^{37,38}$ we found that subjects who had heard about the HPV vaccine from doctors, nurses, health professionals, and community health workers were less likely than others to be willing to pay for the vaccine. Several studies have pointed out that the high cost of the HPV vaccine is a major barrier to recommending the HPV vaccine..$^{39,40}$ More affordable alternatives, such as using condoms and having a single sexual partner, may be prioritized. This could orientate people towards alternatives other than HPV vaccination. Future studies should draw attention to physicians' perceived barriers to recommending HPV vaccine. This may enrich the understanding about barriers to expanding HPV vaccine from the physician's perspective.

Several recommendations can to be drawn from the study. First, sexual health education should be extensively implemented in dynamic forms such as media, workshops, and school curriculums to promote KAP about HPV vaccination among the target populations. Second, the government should mobilize financial resources to reduce the cost of the HPV vaccine. Finally, there needs to be a strong collaboration among stakeholders to introduce the HPV vaccine into the National Immunization Program. Future research could focus on physicians' perceived barriers to recommending the HPV vaccine in the context of Vietnam, and the characteristics of those people who know little about HPV and are not willing to pay for the HPV vaccine.

This study reflects viewpoints from both males and females, which allows us to capture a more comprehensive picture of KAP and WTP for the HPV vaccine in the general population. However, we acknowledge several limitations. First, owing to the nature of the design, we cannot establish causal links between WTP for the HPV vaccine and its associated factors. Second, we recruited our sample by using the convenience sampling technique, which limits the capacity to generalize our results to other settings. Moreover, this study was carried in the vaccination clinic, where people may have better KAP and a high WTP for the HPV vaccine than those in the community. Finally, although some preventive procedures were followed, recall bias and social desirability bias may have occurred, which could affect the main findings of this study.

\section{Conclusion}

Most subjects in this study had misconceptions about the target group for HPV vaccination, and the vaccination rate was low, especially in males. The majority was willing to pay for the vaccine and the average amount they were willing to pay was 1.119 million VND per dose. Age, monthly household income, having children above 6 years old, and sources of hearing about HPV were factors associated with WTP and the amount that people were willing to pay for the HPV vaccine. Enhancing sexual health education among adolescents, reducing the costs of the HPV vaccine, and 
introducing the HPV vaccine into the National Immunization Program could be pragmatic solutions to increase levels of HPV vaccination.

\section{Data sharing statement}

The data from this study are available from the Institute for Preventive Medicine and Public Health, Hanoi Medical University, but restrictions apply to the availability of these data, which were used under license for the current study and so are not publicly available. However, data are available from the authors upon reasonable request and with permission from the Institute for Preventive Medicine and Public Health, Hanoi Medical University.

\section{Acknowledgments}

The authors would like to acknowledge the support of Hanoi Medical University in the implementation of the study. No funding was received for this analysis.

\section{Author contributions}

BXT, PTQT, and TTND conceived the study. BXT, PTQT, CAL, MWBZ, and RCMH designed the study. TTND, HLTN, and HTL implemented the study. BXT, PTQT, HLTN, HTM, and THTN analyzed the data. BXT, PTQT, TTND, HLTN, HTL, HTM, and THTN produced the first draft of the manuscript. All authors contributed toward data analysis, drafting and revising the paper and agree to be accountable for all aspects of the work. All authors read and approved the final manuscript.

\section{Disclosure}

The authors report no conflicts of interest in this work.

\section{References}

1. Bruni L, Barrionuevo-Rosas L, Albero G, et al. Human Papillomavirus and Related Diseases in the World. ICO/IARC Information Centre on HPV and Cancer (HPV Information Centre). Summary Report 27 July 2017. Available from: http://www.hpvcentre.net/statistics/reports/ XWX.pdf. Accessed February 2, 2018.

2. de Martel C, Ferlay J, Franceschi S, et al. Global burden of cancers attributable to infections in 2008: a review and synthetic analysis. Lancet Oncol. 2012;13(6):607-615.

3. Miralles-Guri C, Bruni L, Cubilla AL, Castellsagué X, Bosch FX, de Sanjosé S. Human papillomavirus prevalence and type distribution in penile carcinoma. J Clin Pathol. 2009;62(10):870-878.

4. Gervais F, Dunton K, Jiang Y, Largeron N. Systematic review of costeffectiveness analyses for combinations of prevention strategies against human papillomavirus (HPV) infection: a general trend. BMC Public Health. 2017;17(1):283.

5. Quinn S, Goldman RD. Human papillomavirus vaccination for boys. Can Fam Physician. 2015;61(1):43-46.

6. Agosti JM, Goldie SJ. Introducing HPV vaccine in developing countries key challenges and issues. $N$ Engl J Med. 2007;356(19):1908-1910.
7. Rajiah K, Maharajan MK, Chin NS, Num KS. Awareness and acceptance of human papillomavirus vaccination among health sciences students in Malaysia. Virusdisease. 2015;26(4):297-303.

8. Al-Nuaimi NS, Al-Ghas YS, Al-Owais AH, et al. Human papillomavirus vaccination uptake and factors related to uptake in a traditional desert city in the United Arab Emirates. Int J STD AIDS. 2011;22(7):400-404.

9. Ritten CJ, Breunig IM. Willingness to pay for programs for the human papillomavirus vaccine on a Rocky Mountain West College Campus. Western Economics Forum. 2013;12(1):15.

10. Uhart M, Adam M, Dahlab A, Bresse X. Loss of chance associated with sub-optimal HPV vaccination coverage rate in France. Papillomavirus Res. 2017;3:73-79.

11. Mupandawana ET, Cross R. Attitudes towards human papillomavirus vaccination among African parents in a city in the north of England: a qualitative study. Reprod Health. 2016;13(1):97.

12. Vu LT, Bui D, Le HT. Prevalence of cervical infection with HPV type 16 and 18 in Vietnam: implications for vaccine campaign. BMC Cancer. 2013;13:53.

13. Juntasopeepun P, Davidson PM, Srisomboon J. Issues and challenges in implementing cervical cancer screenings in the emergence of HPV vaccination in Thailand. Collegian. 2012;19(1):45-50.

14. Chow SN, Soon R, Park JS, et al. Knowledge, attitudes, and communication around human papillomavirus (HPV) vaccination amongst urban Asian mothers and physicians. Vaccine. 2010;28(22):3809-3817.

15. Kamimura A, Trinh HN, Weaver S, et al. Knowledge and beliefs about HPV among college students in Vietnam and the United States. J Infect Public Health. 2018;11(1):120-125.

16. Ouedraogo N, Müller O, Jahn A, Gerhardus A. Human papillomavirus vaccination in Africa. Lancet. 2011;378(9788):315-316.

17. Gilmour S, Kanda M, Kusumi E, Tanimoto T, Kami M, Shibuya K. HPV vaccination programme in Japan. Lancet. 2013;382(9894):768.

18. Poulos C, Yang JC, Levin C, Van Minh H, Giang KB, Nguyen D. Mothers' preferences and willingness to pay for HPV vaccines in Vinh Long Province, Vietnam. Soc Sci Med. 2011;73(2):226-234.

19. LaMontagne DS, Barge S, Le NT, et al. Human papillomavirus vaccine delivery strategies that achieved high coverage in low- and middle-income countries. Bull World Health Organ. 2011;89(11):821B-830B.

20. Levin CE, Van Minh H, Odaga J, et al. Delivery cost of human papillomavirus vaccination of young adolescent girls in Peru, Uganda and Viet Nam. Bull World Health Organ. 2013;91(8):585-592.

21. Gavi (The Vaccine Alliance). Countries eligible for support. Gavi; 2017. Available from: https://www.gavi.org/support/sustainability/ countries-eligible-for-support/. Accessed February 2, 2018.

22. Gattoc L, Nair N, Ault K. Human papillomavirus vaccination: current indications and future directions. Obstet Gynecol Clin North Am. 2013; 40(2):177-197.

23. Fontenot HB, Fantasia HC, Charyk A, Sutherland MA. Human papillomavirus (HPV) risk factors, vaccination patterns, and vaccine perceptions among a sample of male college students. J Am College Health. 2014; 62(3):186-192.

24. Nguyen TNT, Phan TL, Ngo VT, Nguyen TTD, Vo HP, Nguyen T. Knowledge and practices of HPV vaccination to prevent cervical cancer among women aged 15-49 in Binh Dinh province, 2017. Vietnam J Prevent Med. 2017;27(8):246.

25. Remschmidt C, Walter D, Schmich P, Wetzstein M, Deleré Y, Wichmann O. Knowledge, attitude, and uptake related to human papillomavirus vaccination among young women in Germany recruited via a social media site. Hum Vaccine Immunother. 2014;10(9):2527-2535.

26. Rondy M, van Lier A, van de Kassteele J, Rust L, de Melker H. Determinants for HPV vaccine uptake in the Netherlands: a multilevel study. Vaccine. 2010;28(9):2070-2075.

27. Brown DS, Johnson FR, Poulos C, Messonnier ML. Mothers' preferences and willingness to pay for vaccinating daughters against human papillomavirus. Vaccine. 2010;28(7):1702-1708.

28. Fesenfeld M, Hutubessy R, Jit M. Cost-effectiveness of human papillomavirus vaccination in low and middle income countries: a systematic review. Vaccine. 2013;31(37):3786-3804. 
29. The World Bank. GDP per capita (current US\$). Available from: https:// data.worldbank.org/indicator/NY.GDP.PCAP.CD?end=2016\&location $\mathrm{s}=\mathrm{VN} \&$ start $=1985 \&$ view $=$ chart. Accessed February 2, 2018.

30. Trinh T, Steckler A, Ngo A, Ratliff E. Parent communication about sexual issues with adolescents in Vietnam: content, contexts and barriers. Sex Educ. 2009;9(4):371-380.

31. Kaljee LM, Green M, Lerdboon P, et al. Parent-youth communication and concordance between parents and adolescents on reported engagement in social relationships and sexually intimate behaviors in Hanoi and Khanh Hoa Province, Vietnam. J Adolesc Health. 2011;48(3): 268-274.

32. Wigle J, Coast E, Watson-Jones D. Human papillomavirus (HPV) vaccine implementation in low and middle-income countries (LMICs): health system experiences and prospects. Vaccine. 2013;31(37):3811-3817.

33. Dorell C, Yankey D, Jeyarajah J, et al. Delay and refusal of human papillomavirus vaccine for girls, national immunization survey-teen, 2010. Clin Pediatr (Phila). 2014;53(3):261-269.

34. Bednarczyk RA, Curran EA, Orenstein WA, Omer SB. Health disparities in human papillomavirus vaccine coverage: trends analysis from the National Immunization Survey-Teen, 2008-2011. Clin Infect Dis. 2014;58(2):238-241.
35. Mihalovic D. More educated parents less likely to vaccinate and feed children sugar and GMO foods. Health Impact News. Feb. 17, 2016. https://healthimpactnews.com/2013/more-educated-parents-lesslikely-to-vaccinate-and-feed-children-sugar-and-gmo-foods/. Accessed February 2, 2018.

36. Moser W. Why do affluent, well-educated people refuse vaccines? Chicago. Mar. 26, 2014. Available from: http://www.chicagomag. com/city-life/March-2014/Why-Is-Vaccine-Refusal-More-PrevalentAmong-the-Affluent/. Accessed February 2, 2018.

37. Allen JD, Othus MK, Shelton RC, et al. Parental decision making about the HPV vaccine. Cancer Epidemiol Biomarkers Prev. 2010; 19(9):2187-2198.

38. Cates JR, Shafer A, Carpentier FD, et al. How parents hear about human papillomavirus vaccine: implications for uptake. J Adolesc Health. 2010;47(3):305-308.

39. Farias AJ, Savas LS, Fernandez ME, et al. Association of physicians perceived barriers with human papillomavirus vaccination initiation. Prev Med. 2017;105:219-225.

40. Wong LP. Issues surrounding HPV vaccine delivery in a multi-ethnic country in Asia: the physician's perspective. J Community Health. 2011;36(1):14-22.

\section{Publish your work in this journal}

Patient Preference and Adherence is an international, peer-reviewed, open access journal that focuses on the growing importance of patient preference and adherence throughout the therapeutic continuum. Patient satisfaction, acceptability, quality of life, compliance, persistence and their role in developing new therapeutic modalities and compounds to optimize clinical outcomes for existing disease states are major areas of interest for the journal. This journal has been accepted for indexing on PubMed Central. The manuscript management system is completely online and includes a very quick and fair peer-review system, which is all easy to use. Visit http://www dovepress.com/testimonials.php to read real quotes from published authors. 